\title{
If Aging is a Disease, then it is Your Own Fault
}

Suresh IS. Rattan*

Department of Molecular Biology and Genetics, Aarhus University, Denmark

"Corresponding author: Suresh I. S. Rattan, Laboratory of Cellular Ageing, Department of Molecular Biology and Genetics, Aarhus University, Denmark, E-mail: rattan@mb.au.dk

Received date: June 22, 2016, Accepted date: June 22, 2016, Published date: June 29, 2016

Copyright: ( 2016 Rattan SI. This is an open-access article distributed under the terms of the Creative Commons Attribution License, which permits unrestricted use, distribution, and reproduction in any medium, provided the original author and source are credited.

Citation: Rattan SI (2016) If Aging is a Disease, then it is Your Own Fault. J Aging Sci 4: e120. doi:10.4172/2329-8847.1000e120

\section{Editorial}

The world of biogerontologists is divided, at present, in two groups. The first would label aging and old age as a disease that needs to be and can be treated. And the second considers aging as a natural continuum of life that needs appropriate management and acceptance. "Aging is a disease" and "waging war against aging" rhetoric may have some role to play in attracting the attention of business investors; it totally disregards the attained understanding of the biological and evolutionary basis of aging. Biogerontological research has shown that there are no definitive and deterministic causes, including gerontogenes, which shape the course of aging and the time of death of an individual. Aging is an emergent phenomenon during the period of survival beyond the essential lifespan (ELS) of a species.

The very act of living constantly causes damage in cells, tissues and organs. Free radicals formed due to external factors and internal metabolism cause molecular damage. Nutritional components sugars, fats and their metabolites cause molecular damage. Biochemical processes of DNA duplication, RNA transcription, protein synthesis and post-translational modifications make spontaneous errors and epigenetic alterations. These destructive acts are counter-balanced by a complex and dynamic network of molecular, cellular and physiological maintenance and repair systems (MARS). Evolutionary processes of selection for survival have developed MARS that control the damage and assure the survival of the species until at least the ELS. MARS, however, are neither perfect nor immune to becoming damaged and inefficient themselves.

The ability of survival through MARS comprised of stress responses, damage control and constant remodelling and adaptation is termed homeodynamics, and is measured as homeodynamic space of an individual. Failure of maintenance leads to the shrinkage of the homeodynamic space that, in turn, increases the chances of crossing the threshold for getting labelled as one or the other age-related disease. Treatment or management of age-related diseases surely demands much more research and development. Each disease may have its own specific mode and targets. However, interventions in aging need to be more than single target- or single pathway-oriented approach.

A promising wholistic approach towards achieving healthy aging is that of hormesis for maintaining health and homeodynamics. There is no denying the fact that chronic, severe and unwanted stress is health-harmful. But there is also a lot of evidence that shows that low level and repeated "stress of choice" is good and health-beneficial. Moderate and repeated physical exercise is the best example of hormesis. MARS-based cellular responses to mild stress protect the body and strengthen the homeodynamics. Hormetins are the conditions that induce hormesis, and are categorised as nutritional-, physical- and mental hormetins. Food components in spices and micronutrients are nutritional hormetins. Life style practices, such as sauna, breath control, mental challenges and proactive social engagement, are other examples of physical and mental hormetins. Novel combinations of multi-hormetins are under scientific investigation.

The science of aging - Gerontology, and its specialisations Biogerontology, Sociogerontology, Psychogerontology - deals with the continuum of life and its eventual termination. Geriatrics is the clinical treatment and management of diseases of old age. Some scientists have proposed recently the term Geroscience combining the science of aging and the practice of prevention, management and treatment of all age-related conditions. But if you still consider that aging is a disease like any other disease, then it is your own fault: you breathe, you eat, you metabolise. Just think about it. 